\section{MANAGEMENT OF HEAT STROKE PATIENTS: A STUDY OF THREE YEARS EXPERIENCE}

\author{
Mohamed A. Seraj, M.D., Ryiadh, Saudi Arabia
}

The presentation is based on Heat Stroke Center at the city of Mena where a large number visit annually as one of the Islamic holy places for pilgrimage (Haji). Rituals are performed in a sandy valley with temperatures ranging from $30-50^{\circ} \mathrm{C}$ with relative humidity of 25 to $50 \%$. Illnesses are presented as heat cramps, exhaustion or stroke. This last one is less common and characterized by hyperpirexia above $40^{\circ}$, anhydrosis and CNS disturbances from confusion to convulsions and coma. Being the most severe form of heat illness has high mortality rate.

In our experience the predisposing factors have been confirmed as high temperature, humidity and excessive physical exertion among unaclimatized pilgrims who come from many different points not having such extreme conditions as those found in the pilgrimage holy places. Contributory unfavorable factors are related to overcrowded places, old age, obesity, diabetes mellitus and respiratory or cardiac disease.

Preventive facilities provided by the Ministery of Health are numerous and distributed throughout the holy cities as Stroke Centers well equipped and professionally staffed. Anesthetists are in charge as members of the team with an unanimously accepted vital role, as they are skilled in airway management, ventilation control, correction of fluid and electrolytes and acid base disturbances, cardiopulmonary resuscitation and intensive care management. They are also responsible for health personnel training such as medical students, ambulance attendants and doctors, and organizing new research projects.

In the last three years the number of anesthetists participating in the management of heat stroke patients has increased while mortality rate decreased very pronouncedly. Two new techniques of body cooling have been widely used and critically investigated by members of the medical teams in those Centers. The results of treatment of several thousand heat stroke victims during Hajj season will be discussed with special emphasis on the Heat Stroke Center No. 1 (Mena).

\section{REVERSIBILITY OF CLINICAL DEATH}

\author{
Peter Safar, M.D., Pittsburgh, \\ Pennsylvania, U.S.A.
}

Recent research into dying patterns and their reversibility has been reviewed (1-3) and discussed among active investigators, to explore research hypotheses, ideas, and approaches (4). Conclusions and recommendations of a researchers' symposium on clinical death of May 2-4, 1987 will be presented.

Present concepts on biologic limits to the reversibility of clinical death are: normothermic ventricular fibrillation (VF) cardiac arrest (CA) (no flow) of 20 min (not $5 \mathrm{~min}$ ), similar for brain and heart; hypothermic CA of 60 min or longer. Present therapeutic potentials, with optimal CPR-ALS, artificial circulation, etc., seem to be $>10 \mathrm{~min}$ for normothermic VF CA (no flow)-shorter for asphyxial CA, longer for exsanguination CA. Present predictions of outcome with severe brain damage (important for critical care triage) are better for CA than for head injury. Escalating research activities are attempting to make therapeutic potentials approach biologic limits. This is causing ethical dilemmas for resuscitation medicine, magnified in disasters.

\section{References}

1. Safar P: The pathophysiology of dying and reanimation. In, Princ Pract of Emergency Medicine (2nd ed.). Schwartz et al (eds). Saunders Publ., 1986.

2. Safar $\mathbf{P}$, Bircher N: Cardiopulmonary-Cerebral Resuscitation. Introd. to Resusc. Med. 3rd ed. 1987. WFSA; A. Laerdal Publ.; Saunders Publ.

3. Safar P: Cerebral resuscitation. Circulation 74(suppl IV):138, 1986.

4. Safar P, et al (eds): Intl Resus Research Symposium on the Reversibility of Clin Death, Pittsburgh, May 2-4, 1987. In preparation for Crit Car Med. 